\title{
The concept of the formation of socio-personal viability in adolescents with deviant behavior
}

\author{
Maria Paatova ${ }^{1, *}$, Kazbek Chermit $^{1}$, and Yuri Naumenko ${ }^{2}$ \\ ${ }^{1}$ Adyghe State University, 385000, 208 Pervomaiskaya Str., Maikop, Russia \\ ${ }^{2}$ Volgograd State Academy of Physical Culture, 400005, 78 Lenin ave., Volgograd, Russia
}

\begin{abstract}
The paper critically reviews the concept that focuses on the formation of social and persona; viability in adolescents with deviant behavior. Rely on extensive scholarly literature published in Russia and abroad, the authors describe the concept and its essential features. Additionally, statistical analysis of the distribution of pedagogues of pupils of four special closed educational institutions for students with deviant (socially dangerous) behavior according to the levels of social and personal viability is used to illustrate the concept.
\end{abstract}

An analysis of psychological and pedagogical studies devoted to the phenomenon of "vitality" (M. P. Guryanova, I. P. Il'inskii, L. G. Dikaya, A. I. Laktionova, A. V. Makhnach, Yu. V. Naumenko, A. A. Nesterova, E. A. Rylskaya, etc.) allowed us to formulate an author's understanding of the essence of social and personal viability as an integrative personal quality that characterizes the individual's readiness for self-determination (moral, personal, social, professional) according to his/her own life scenario, as well as the willingness to manage this scenario and be responsible for the results of their decisions on life self-determination.

The results of the study of scientific literature on this subject allow us to present the following structure of social-personal viability: (a) a system-forming element - existential (socially oriented and positively developing sense-purposes); (b) the integrated elements co-subordinated to his/her-emotional-behavioral (positive attitude towards other people and themselves, the adoption of socio-cultural norms, values, laws, and readiness to review the meaning of their existence in accordance with them) and motivational-volitional (sustainable and conscious motivation to long-term efforts to change oneself to achieve personal well-being in accordance with conscious and accepted existing socio-cultural values and norms).

As a result of the analysis of works devoted to viability and in which different levels of its manifestation are distinguished (M. P. Guryanova, A. I. Laktionova, A. V. Makhnach, Y. V. Naumenko, A. A. Nesterova, E. A. Rylskaya, etc.), four levels of development of social-personal viability are singled out: (1) the level of negative attitude towards sociocultural rules and norms of life activity; (2) the level of neutrally adaptive attitude to sociocultural rules and norms of life; (3) the level of incomplete (partial) adoption of socio-

\footnotetext{
* Corresponding author: naymenko.yv@yandex.ru
} 
cultural norms and rules of life; and (4) the level of acceptance of socio-cultural norms and rules of life.

The allocated levels of socio-personal viability are described in the following indicators: dogmatism-variability; awareness in the adoption of life values; spiritual or consumer orientation; and temporary localization.

Statistical analysis of the distribution of pedagogues of pupils of four special closed educational institutions for students with deviant (socially dangerous) behavior (422 in all) according to the levels of social and personal viability (April-May 2010) showed the following: (1) among pupils of all special closed-type educational institutions are not adolescent deviants who accept socio-cultural norms and rules of life; (2) the largest group consists of pupils with a neutrally adaptive attitude to socio-cultural rules and norms of life activity; (3) the second largest group is the pupils with a negative attitude to socio-cultural rules and norms of life; (4) the percentage of pupils with a negative attitude to sociocultural rules and norms of life and pupils with a neutral adaptation to socio-cultural rules and norms of life corresponds to the percentage ratio of adolescent deviants who do not associate themselves with a person who can influence the course of their lives and change their destiny; (5) the percentage of adolescents with an active form of deviant behavior coincides with the percentage of pupils with a negative attitude to socio-cultural rules and norms of life; (6) the percentage ratio of adolescents with a passive form of deviant behavior coincides with a neutrally adaptive attitude to socio-cultural rules and norms of life activity and with incomplete (partial) adoption of socio-cultural norms and rules of life.

In this regard, we consider the social and pedagogical rehabilitation of adolescents with deviant behavior in special closed-type educational institutions as a specially organized pedagogical process within the framework of general education aimed at certain changes in the value and semantic sphere of the personality of adolescents with deviant behavior in order to form their socio-personal viability (the adoption of socio-cultural norms, the rules of life, and the readiness of adolescents to manifestation of social but-personal viability in various situations of daily living) as the necessary conditions for the return to society and further successful socialization.

The tasks of social and pedagogical rehabilitation of adolescents with deviant behavior for the formation of social and personal viability in the conditions of special closed educational institutions are: (1) the formation of socially-oriented and positively developing sense-based attitudes; (2) the formation of a sustainable and conscious motivated involvement in the development of individual subjectivity in accordance with the sense of life; (3) the formation of the readiness of adolescents to manifest their social-personal viability in different situations of daily life activity.

As a means of shaping the social and personal viability of adolescents with deviant behavior in the process of social and pedagogical rehabilitation, the rehabilitation and educational situation is a specially planned event-related life and a personality-affirming situation, which affect the vital interests of the adolescent deviant and forces to harmonize the social-personal vitality.

Relying on the typology of personality-affirming situations (S. V. Belova, V. I. Danilchuk, E. A. Kryukova, V. V. Serikov, etc.) and analysis of real experience of social and pedagogical rehabilitation of deviant adolescents in special educational and educational institutions of the Republic of Adygea and Tula region, the following types of rehabilitation and educational situations are substantiated: (a) the situation of success in socially significant and personally attracting activities that contribute to the emergence of a desire to re-experience success, overcoming all difficulties; (b) the situation of "collision" of a teenager with events, the world of things and deeds in which they experience a shortage of social and personal competence and a desire to improve oneself awakens; c) the situation of reflection of one's own progress in the process of harmonization of social-personal viability 
as a result of self-improvement; (d) the situation of finding life values, motives, and goals of one's own life in an open society for further successful socialization; (e) the situation of analyzing, evaluating, and finding a solution for a teenager of life problems existing in an open society and preventing a person from further successful socialization; (f) the situation of a teenager's meeting with a "significant OTHER," actualizing the need of pupils for selfchange and self-development. Design and use of rehabilitation and educational situations should be differentiated, taking into account the form of manifestation of deviant behavior.

In view of the foregoing, the educational and information function of the social and pedagogical rehabilitation of deviant adolescents manifests itself in the formation of specific knowledge, skills, and experience of reproductive and creative activity in life selfdetermination and personal self-construction necessary to resolve rehabilitation and educational situations.

The evolving function of the social and pedagogical rehabilitation of deviant adolescents is realized in the essential restructuring of the semantic sphere of the adolescent-deviant personality for the purpose of life self-determination and self-reflection as a result of the application of the mechanisms of sense-awareness and meaningfulness in resolving rehabilitation-educational situations.

The educational function of social and pedagogical rehabilitation of deviant adolescents is manifested in the actualization of the mechanism of self-education with the aim of forming personal qualities necessary for socially approved life activities, realized and accepted as a result of the resolution of rehabilitation and educational situations.

The axiological function of the social and pedagogical rehabilitation of deviant adolescents manifests itself in a change in life attitudes and values as a result of the resolution of rehabilitation and educational situations as a necessary condition for returning to society and further successful socialization.

The function of social adaptation of social and pedagogical rehabilitation of deviant adolescents is manifested in the harmonization of social and personal viability, without the positive manifestation of which successful socialization is impossible.

The social and pedagogical rehabilitation of adolescents with deviant behavior is subject to the general principles of the organization and functioning of the pedagogical process (holistic approach, continuity and goal-oriented education, integration and differentiation of the joint activity of teachers and pupils, education in activity and in the team), as well as specific one - adolescents with deviant behavior of social-personal viability (the principles of actualization of the developing personality and competence areas of socio-pedagogical rehabilitation of teenagers with and deviant behavior).

The structural and functional model of the formation of the social and personal viability of adolescents with deviant behavior in the process of social and pedagogical rehabilitation consists of three stages, each of which consistently solves the problems of shaping the social and personal viability of adolescents with deviant behavior as a necessary condition for their return to society and further successful socialization.

At the first stage - the stage of reassessment of meaningful plants - the task of forming social-oriented and positively developing personalities of meaningful settings among adolescent deviants.

The main pedagogical means are the following types of rehabilitation and educational situations: the situation of searching for life values, motives and goals of one's own life in an open society for further successful socialization; situation of meeting a teenager with a "significant other," actualizing the need of pupils for self-change and self-development.

The result of the first stage should be the following changes in the structure of the social and personal viability of adolescent deviantas: (1) in the existential component - sociallyoriented sense of life, when assessing the majority of events, will play a decisive role; (2) in the emotional-behavioral component - in most situations, will begin to manifest: a) positive 
criticality to yourself and your life in all its forms and manifestations, as well as its results; b) the ability to clarify the meaning of their existence, depending on the change of life circumstances and in accordance with socially-oriented meaningful concepts; (3) in the motivational and volitional component, there will be a desire to change oneself to achieve personal well-being in accordance with the realized and accepted existing socio-cultural values and norms.

At this stage, the following functions of the social and pedagogical rehabilitation of adolescent deviantas are being updated: (a) axiological function (changing life attitudes and values as a result of resolving rehabilitation and educational situations as a necessary condition for returning to society and further successful socialization); (b) an evolving function (a significant rearrangement of the semantic sphere of the adolescent-deviant personality for the purpose of life self-determination and self-reflection as a result of the application of the mechanisms of sense-awareness and meaningfulness in resolving the system of rehabilitation and educational situations).

At the second stage, the stage of the formation of practical skills in the implementation of socially-oriented sense-of-life settings, the problem of forming teenagers-deviants' readiness for the manifestation of social-personal viability in various real-life situations.

The main pedagogical means are the following types of rehabilitation and educational situations: the situation of reflection of one's own progress in the process of harmonization of social and personal viability as a result of self-improvement; the situation of searching for life values, motives, and goals of one's own life in an open society for further successful socialization; the situation of analysis, evaluation and finding a solution for a teenager life problems that exist in an open society and interfere with him in the further successful socialization.

The result of the second stage should be the following changes in the structure of the social and personal viability of adolescent deviantas: (1) in the existential component, socially-oriented meaningful attitudes become decisive in the modeling of individual behavior; (2) in the emotionally-behavioral component - in most situations, it will begin to manifest: (a) a positive attitude towards other people and themselves; (b) the ability to clarify the meaning of their existence, depending on the change of life circumstances and in accordance with socially-oriented sense of life; (c) the ability to control one's behavior in accordance with social norms, rules, and laws; (d) the ability to positively plan their life activities and implement this plan in general terms; (3) in the motivational and volitional component, there will be a willingness to change oneself to achieve personal well-being in accordance with conscious and accepted existing social and cultural values and norms, with the support of the educator.

At this stage, the following functions of the social and pedagogical rehabilitation of adolescent devotees are updated (in addition to the functions involved in the first stage): (a) the educational and information function (the formation of specific knowledge, skills, and experience of reproductive creative activity in life self-determination and personal selfconstruction, which is necessary to resolve rehabilitation and educational situations); (b) the function of social adaptation (the formation of experience in resolving the life situations of self-determination in an open society).

At the third stage, the stage of forming readiness for positive changes in an open society, the task of forming the experience of realizing social and personal viability in various situations of daily life.

The main pedagogical means are the following types of rehabilitation and educational situations: the situation of reflection of one's own progress in the process of harmonization of social and personal viability as a result of self-improvement; the situation of searching for life values, motives and goals of one's own life in an open society for further successful socialization; the situation of analysis, evaluation, and search for a solution of the 
teenager's life problems existing in an open society and preventing him/her from further successful socialization; the situation of success in socially significant and personally attracting activities, which contributes to the emergence of a desire to re-experience success, overcoming all difficulties.

The result of the third stage should be the following changes in the structure of the social and personal viability of adolescent deviantas: (1) in the existential component, socially-oriented meaningful attitudes become decisive in the modeling of individual behavior; (2) in the emotional-behavioral component, it is stably manifested: a) the ability to clarify the meaning of their existence, depending on the change of life circumstances and in accordance with socially-oriented sense of life; (b) the ability to control one's behavior in accordance with social norms, rules, and laws; c) the ability to positively plan their life activities and implement this plan in general terms; 3 ) in the motivational and volitional component, the readiness for long independent efforts to change oneself to achieve personal well-being in accordance with the conscious and accepted existing socio-cultural values and norms.

At this stage, in addition to the functions involved in the first and second stages, the educational function of the social and pedagogical rehabilitation of adolescent deviantes will be updated (the actualization of the mechanism of self-education with the purpose of forming personal qualities necessary for socially approved life activities as a result of the resolution of rehabilitation and educational situations).

\section{References}

1. M. E. Paatova, Social and pedagogical rehabilitation of adolescents with deviant behavior in special educational institutions of closed type: theory and practice (MISiS Publishing House, Moscow, 2015)

2. M. E. Paatova, Formation of social and personal viability of deviant teenagers in the process of social and pedagogical rehabilitation: theoretical and methodological foundations (Publishing house of the journal "Questions of political science," Moscow, 2017)

3. M. E. Paatova, Pedagogy, 2 (2010)

4. M. E. Paatova, Yu. V. Naumenko, Narodnoye Obrazovaniye, 7 (2013)

5. M. E. Paatova, European Social Science Journal, 9, 2 (2014)

6. M. E. Paatova, Pedagogika, 5 (2016)

7. M. E. Paatova, Bulletin of the Adyghe State University - Series in Pedagogy and Psychology, 1, 193 (2017)

8. M. E. Paatova, Yu. V. Naumenko, Proceedings of the Saratov University - Series in Philosophy, Psychology, Pedagogy, 17, 2 (2017) 